\title{
PENGEMBANGAN ALAT PENGUKUR CEPAT RAMBAT BUNYI MENGGUNAKAN SENSOR ULTRASONIK SEBAGAI MEDIA PEMBELAJARAN FISIKA SMA
}

\author{
Zulfikar $^{\text {a) }}$, Cecep E Rustana ${ }^{\text {b) }}$, Widyaningrum Indrasaric ${ }^{\mathrm{c})}$ \\ Program Studi Pendidikan Fisika Fakultas Matematika dan Ilmu Pengetahuan Alam, Universitas Negeri \\ Jakarta Jalan Rawamangun Muka No.1 Rawamangun, Jakarta Timur 13220 \\ Email: ${ }^{\text {a) }}$ zoelfikaremail@gmail.com, ${ }^{\text {b) }}$ ce.rustana@yahoo.com, ${ }^{\mathrm{c})}$ widyafisikaunj@gmail.com
}

\begin{abstract}
Abstrak
Gelombang bunyi adalah salah satu materi pembelajaran fisika yang dianggap sulit oleh peserta didik. Salah satu penyebab hal tersebut adalah guru fisika hanya mengajar dengan media pembelajaran yang seadanya. Berdasarkan analsis kebutuhan yang telah dilakukan, sebagian besar guru fisika mengajarkan materi gelombang bunyi dengan menggunakan media berupa powerpoint. Penelitian ini bertujuan untuk mengembangkan alat praktikum pengukur cepat rambat bunyi di udara dengan menggunakan sensor ultrasonik. Alat ini menggunakan sensor ultrasonik HC-SR04 sebagai pembangkit gelombang ultrasonik dan menggunakan mikrokontroler arduino sebagai sistem kontrol alat praktikum. Hasil dari pengukuran cepat rambat bunyi menggunakan alat ini adalah 342,9986038 m/s dengan presentase error sebesar $0,004294504 \%$.
\end{abstract}

Kata-kata kunci : Alat Praktikum, Cepat Rambat Bunyi, Sensor Ultrasonik

\begin{abstract}
Sound waves are one of the physics learning materials that are considered difficult by students. One of the causes of that is the physics teacher only teaches with a simple learning media. Based on the needs analysis, most physics teachers teach sound wave topics using a PowerPoint. The research aims to develop a practicum tool that can measure sound velocity in the air using an ultrasonic sensor. The tool uses the ultrasonic sensor HC-SR04 as an ultrasonic wave generator and uses the Arduino microcontroller as a control system for practicum tools. The result of a quick measurement of sound velocity using this tool is $342.9986038 \mathrm{~m} / \mathrm{s}$ with a percentage error of $0.004294504 \%$.
\end{abstract}

Keywords : Practicum tool, Sound velocity, ultrasonic sensor

\section{PENDAHULUAN}

Salah satu materi pembelajaran fisika yang dianggap sulit oleh peserta didik adalah materi gelombang bunyi. Materi gelombang pada pembelajaran fisika dianggap sulit oleh peserta didik karena banyaknya konsep yang bersifat abstrak ditambah dengan rumus yang digunakan sedangkan 
sebagian besar guru hanya mengajar dengan metode ceramah sehingga peserta didik menjadi cepat lupa akan materi gelombang yang telah diajarkan [1]. Pembelajaran fisika dapat menjadi lebih konkrit apabila peserta didik belajar dengan menggunakan media pembelajaran. Berdasarkan analisis kebutuhan yang telah dilakukan, pembelajaran fisika di dalam kelas umumnya hanya menggunakan media pembelajaran berupa papan tulis dan PowerPoint. Penggunakan media pembelajaran dapat meningkatkan minat dan motivasi peserta didik. Penggunaan media pembelajaran dalam proses pembelajaran dapat membantu peserta didik untuk memperoleh pemahaman yang lebih baik, menyajikan data yang menarik dan terpercaya, memudahkan penafsiran data, dan memadatkan informasi. Peserta didik yang belajar dengan menggunakan media pembelajaran akan cenderung lebih tertarik belajar dibandingkan dengan peserta didik yang hanya mendengar ceramah dari guru [2].

Ada beragam metode pembelajaran yang dapat digunakan dalam pembelajaran fisika, salah satunya adalah adalah metode praktikum. Bagi peserta didik, kegiatan praktikum adalah kegiatan yang dilakukan peserta didik untuk menemukan konsep atau prinsip yang baru. Metode praktikum dapat menumbuhkembangkan rasa ingin tahu peserta didik, aktif, kreatif, inovatif, dan kejujuran ilmiah dalam menghadapi suatu masalah dalam realita kehidupan [3]. Oleh karena itu, perlu dikembangkan alat praktikum yang dapat menunjang pembelajaran fisika khususnya dalam materi gelombang bunyi. Penelitian ini bertujuan untuk mengembangkan alat praktikum pengukur cepat rambat bunyi di udara dengan menggunakan sensor ultrasonik.

\section{METODOLOGI PENELITIAN}

Metode penelitian yang digunakan untuk mengembangkan alat praktikum pengukur cepat rambat bunyi adalah metode penelitian Research and Development dengan model pengembangan ADDIE. Model pengembangan ADDIE dipilih karena memiliki langkah-langkah yang tepat untuk mengembangkan media pembelajaran atau perangkat pembelajaran lainnya [4]. Beberapa perangkat pembelajaran yang menggunakan model ADDIE adalah pengembangan aplikasi mobile berbasis Android [5], blended learning [6], dan buku petunjuk penggunaan simulasi [7]. Tahapan penelitian pengembangan alat praktikum pengukur cepat rambat bunyi dengan model pengembangan ADDIE tertera pada Tabel 1 berikut.

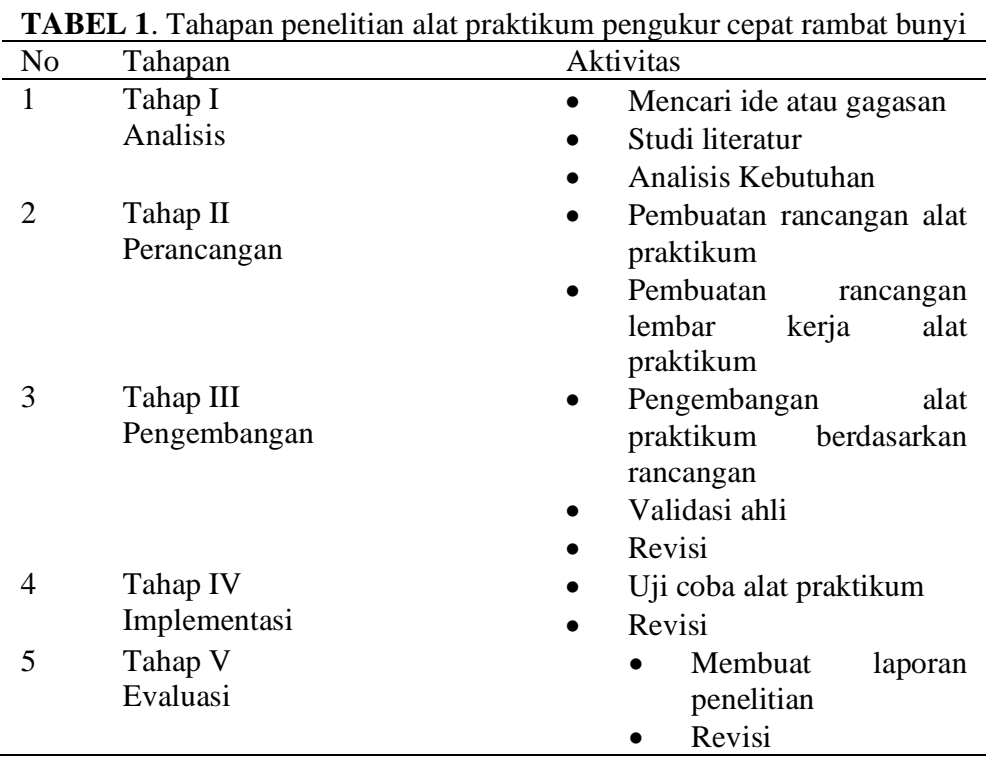


Rancangan alat praktikum pengukur cepat rambat bunyi ditunjukkan pada gambar di bawah ini

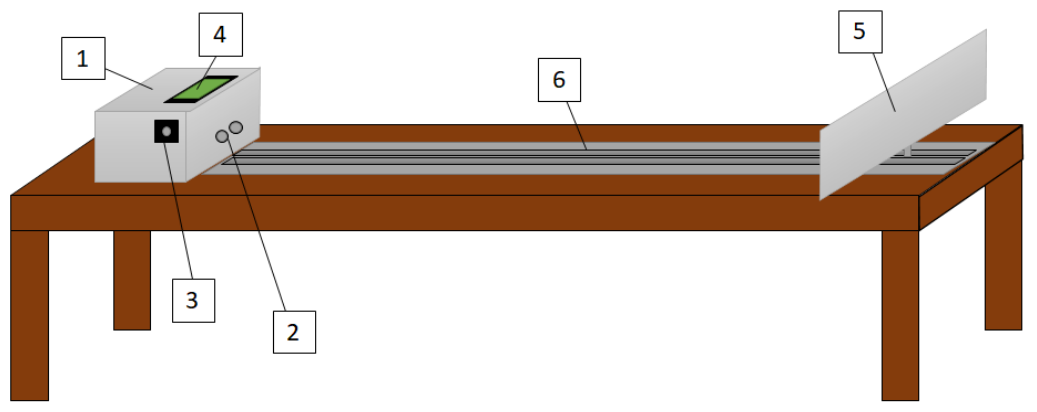

GAMBAR 1. Rancangan alat praktikum pengukur cepat rambat bunyi

TABEL 2. Bagian-bagian alat praktikum pengukur cepat rambat bunyi

\begin{tabular}{|c|c|c|}
\hline No & Bagian alat & Keterangan \\
\hline 1 & Kotak Elektronik & $\begin{array}{l}\text { Berisikan komponen elektronik dan } \\
\text { rangkaian penyusun alat praktikum } \\
\text { pengukur cepat rambat bunyi. }\end{array}$ \\
\hline 2 & Sensor Ultrasonik & $\begin{array}{l}\text { Modul yang dapat memancarkan dan } \\
\text { menerima gelombang ultrasonik. }\end{array}$ \\
\hline 3 & Push Button & $\begin{array}{l}\text { Tombol yang digunakan untuk } \\
\text { memulai operasi pengukuran cepat } \\
\text { rambat bunyi. }\end{array}$ \\
\hline 4 & Liquid Crystal Display (LCD) & $\begin{array}{l}\text { Modul untuk menampilkan data hasil } \\
\text { pengukuran cepat rambat bunyi. }\end{array}$ \\
\hline 5 & Papan Penghalang & $\begin{array}{l}\text { Penghalang yang digunakan untuk } \\
\text { menghalangi pancaran gelombang } \\
\text { ultrasonik pada jarak tertentu. }\end{array}$ \\
\hline 6 & Lintasan Papan Penghalang & $\begin{array}{l}\text { Lintasan lurus yang digunakan untuk } \\
\text { mengubah jarak antara papan } \\
\text { penghalang dan kotak elektronik }\end{array}$ \\
\hline
\end{tabular}

Walaupun di pasaran banyak jenis papan Arduino yang dijual [8]. Alat ini menggunakan Arduino Uno Pada alat ini menggunakan sensor ultrasonik sebagai sumber gelombang ultrasonik dan penerima gelombang ultrasonik. Gelombang yang dipancarkan dari modul sensor ultrasonik adalah gelombang bunyi dengan frekuensi ultrasonik dengan cepat rambat bunyi di udara sebesar $343 \mathrm{~m} / \mathrm{s}$ [9]. Salah satu sifat gelombang adalah dapat dipantulkan. Ketika gelombang ultrasonik menyentuh penghalang yang tegak lurus sumber gelombang, maka gelombang akan akan dipantulkan oleh penghalang dan akan akan dipantulkan kembali menuju modul penerima sensor ultrasonik. Modul sensor ultrasonik akan mencatat selang waktu antara gelombang dipancarkan dan gelombang diterima. Waktu yang dicatat oleh modul akan berbeda-beda bergantung dengan jarak antara modul sensor ultrasonik dengan papan penghalang [10]. Data pengukuran berupa jarak tempuh gelombang ultrasonik dan waktu tempuh ultrasonik akan ditampilkan pada LCD yang ada pada kotak elektronik. Data pengukuran jarak tempuh dan waktu tempuh gelombang ultrasonik dapat digunakan untuk menghitung nilai cepat rambat bunyi di udara. Besar cepat rambat bunyi di udara dapat dihitung dengan persamaan berikut ini.

$$
v=\frac{2 s}{t}
$$

dengan $v$ adalah cepat rambat bunyi di udara, $s$ adalah jarak tempuh gelombang bunyi, dan $t$ adalah waktu tempuh gelombang bunyi.

Modul sensor ultrasonik yang digunakan terlebih dahulu dilakukan kalibrasi untuk menentukan tingkat keakuratan dari modul tersebut. Modul sensor yang digunakan adalah yang memiliki tingkat 
keakuratan yang paling tinggi terhadap alat ukur manual. Untuk menghitung kesalahan relatif dari modul sensor elektronik yang digunakan, maka dihitung dengan menggunakan persamaan berikut ini.

$$
\operatorname{Error}(\%)=\frac{|N s-N r|}{N r} \times 100 \%
$$

dengan Ns adalah nilai yang terbaca pada sensor yang digunakan, dan $\mathrm{Nr}$ adalah nilai sebenarnya yang telah diuji menggunakan alat laboratorium. Selanjutnya modul sensor ultrasonik diletakkan pada rangkaian alat praktikum sesuai dengan rancangan sebelumnya.

\section{HASIL DAN PEMBAHASAN}

\section{Karakterisasi Sensor Ultrasonik}

Karakterisasi sensor ultrasonik dilakukan untuk menentukan tingkat akurasi dari sensor yang digunakan. Karakterisasi dilakukan dengan membandingkan jarak yang terukur oleh sensor ultrasonik dan jarak yang terukur di penggaris. Data yang didapatkan dari sensor ultrasonik berupa selang waktu antara gelombang ultrasonik yang dipancarkan dan diterima oleh sensor ultrasonik.

TABEL 3. Data Karakterisasi Sensor Ultrasonik

\begin{tabular}{cccccc}
\hline $\begin{array}{c}\text { Jarak } \\
\text { Penggaris } \\
(\mathrm{cm})\end{array}$ & $\begin{array}{c}\text { Jarak } \\
\text { Sensor } 1 \\
(\mathrm{~cm})\end{array}$ & $\begin{array}{c}\text { Jarak } \\
\text { Sensor 2 } \\
(\mathrm{cm})\end{array}$ & $\begin{array}{c}\text { Jarak } \\
\text { Sensor 3 } \\
(\mathrm{cm})\end{array}$ & $\begin{array}{c}\text { Jarak Sensor } \\
\text { Rata-rata }(\mathrm{cm})\end{array}$ & $\begin{array}{c}\text { Kesalahan } \\
\text { Relatif }(\%)\end{array}$ \\
\hline 2 & 2,95 & 3,07 & 3,07 & 3,03 & 51,5 \\
5 & 5,44 & 4,87 & 4,97 & 5,093333 & 1,866667 \\
10 & 10,62 & 10,56 & 10,72 & 10,63333 & 6,333333 \\
20 & 20,01 & 20,24 & 20,03 & 20,09333 & 0,466667 \\
30 & 29,91 & 30,06 & 30,39 & 30,12 & 0,4 \\
40 & 39,69 & 40,15 & 40,22 & 40,02 & 0,05 \\
50 & 49,6 & 49,94 & 49 & 49,51333 & 0,973333 \\
60 & 59,46 & 58,96 & 59,77 & 59,39667 & 1,005556 \\
70 & 69,22 & 69,53 & 69,1 & 69,28333 & 1,02381 \\
80 & 79,56 & 80,24 & 79,76 & 79,85333 & 0,183333 \\
90 & 88,61 & 88,19 & 88,89 & 88,56333 & 1,596296 \\
100 & 98,61 & 98,9 & 98,15 & 98,55333 & 1,446667 \\
\hline
\end{tabular}

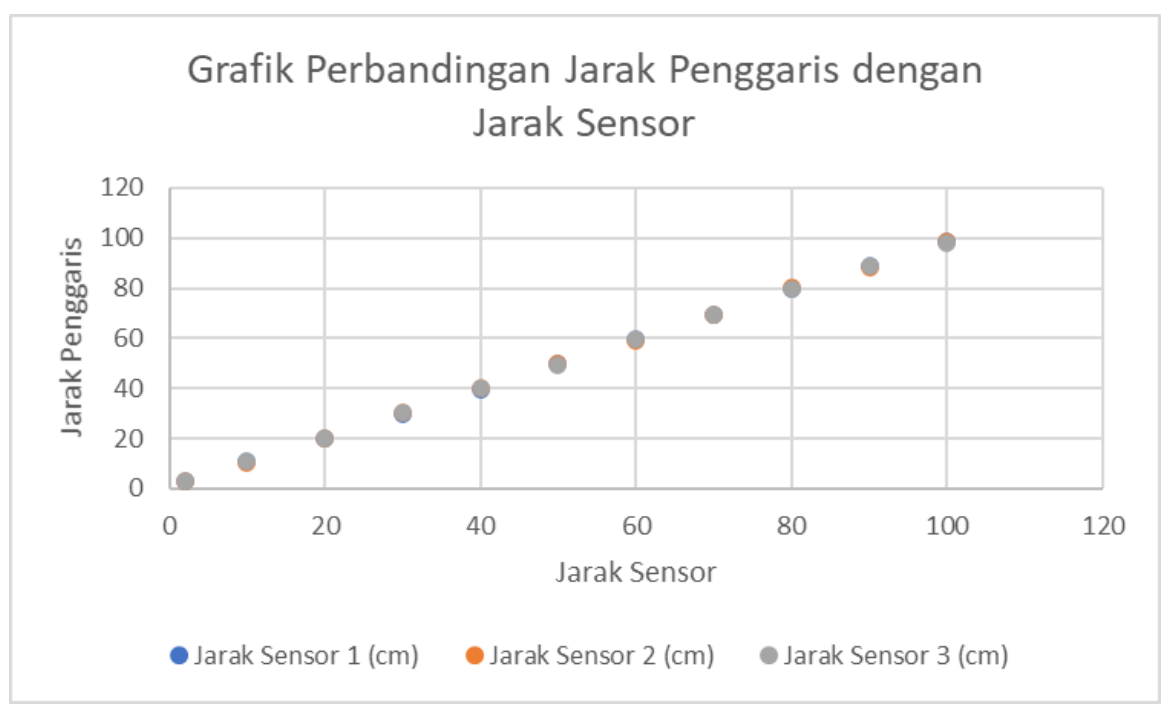

GAMBAR 2. Grafik Perbandingan Jarak Penggaris dengan Jarak Sensor 


\section{Pengukuran Cepat Rambat Bunyi di Udara}

Pada penelitian ini telah dikembangkan alat praktikum pengukur cepat rambat bunyi dengan menggunakan sensor ultrasonik sebagai penunjang pembelajaran fisika pada materi gelombang bunyi. Pengukuran cepat rambat bunyi di udara dilakukan dengan memancarkan gelombang ultrasonik yang akan dihalang oleh papan penghalang pada jarak tertentu. Data yang diterima oleh sensor ultrasonik berupa jarak antara sensor ultrasonik ke papan penghalang dan selang waktu gelombang ultrasonik dipancarkan hingga gelombang diterima kembali oleh sensor. Data yang diterima akan diolah pada mikrokontroler arduino dan akan ditampilkan pada LCD yang terdapat pada rangkaian alat praktikum. Data juga dapat ditampilkan pada bagian Serial Monitor pada Arduino IDE. Data ujicoba alat praktikum pengukur cepat rambat bunyi adalah sebagai berikut :

TABEL 4. Data Pengukuran Alat Praktikum Pengukur Cepat Rambat Bunyi

\begin{tabular}{ccc}
\hline Jarak Papan Penghalang $(\mathrm{cm})$ & Cepat Rambat Bunyi $(\mathrm{m} / \mathrm{s})$ & Kesalahan Relatif $(\%)$ \\
\hline 5 & 343,0446 & 0,013009 \\
10 & 342,9844 & 0,004545 \\
20 & 342,993 & 0,002039 \\
30 & 342,9813 & 0,005453 \\
40 & 343,0131 & 0,00381 \\
50 & 342,9717 & 0,00825 \\
60 & 343,0066 & 0,001913 \\
70 & 342,9966 & 0,000996 \\
80 & 342,9891 & 0,003189 \\
90 & 343,0066 & 0,00191 \\
100 & 343,0006 & 0,000183 \\
\hline
\end{tabular}

Data di atas dapat diplot menjadi grafik sebagai berikut :

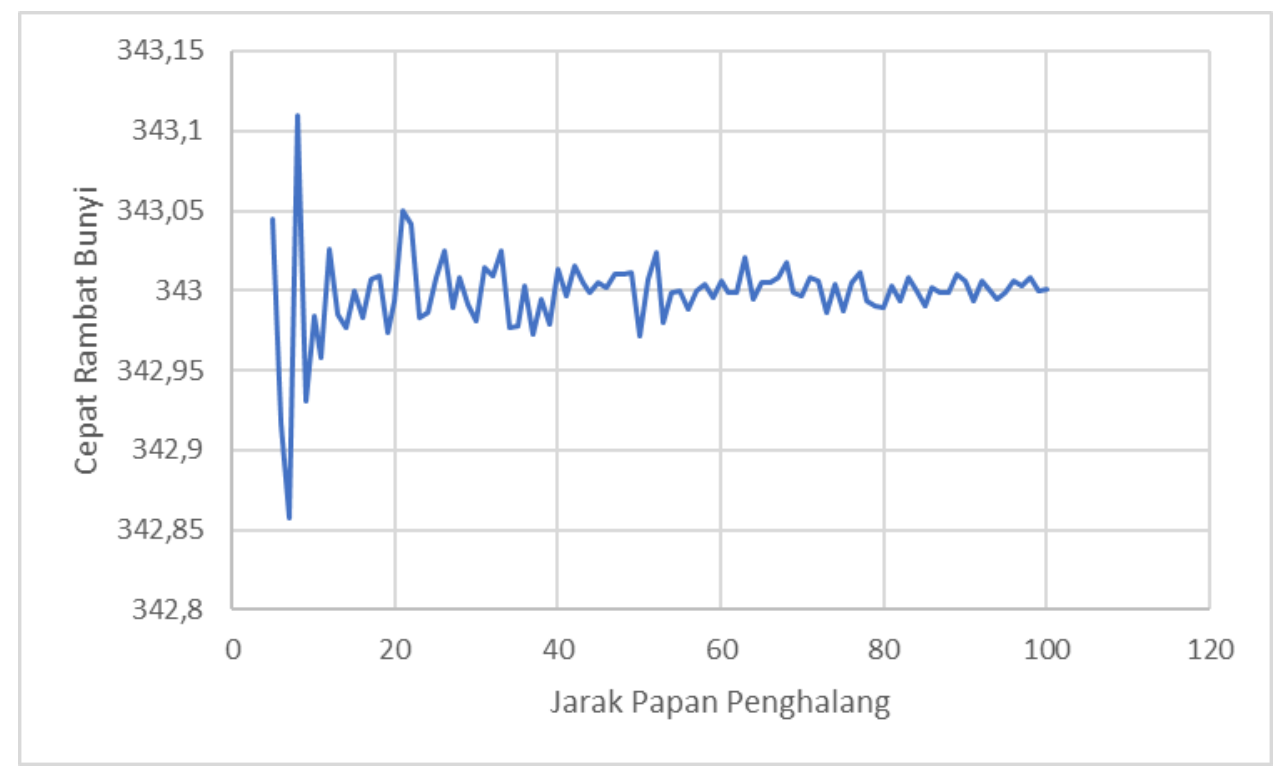

GAMBAR 4. Grafik Cepat Rambat Bunyi pada berbagai jarak papan penghalang

Berdasarkan grafik di atas, pengukuran dengan menggunakan alat praktikum pengukur cepat rambat bunyi memiliki kesalahan relatif yang signifikan pada jarak papan penghalang kurang dari 20 $\mathrm{cm}$ dibandingkan dengan jarak papan penghalang lebih dari $20 \mathrm{~cm}$. Hal tersebut dikarenakan oleh karakteristik dari sensor ultrasonik yang memiliki kesalahan relatif yang cukup besar apabila mendeteksi benda yang berada pada jarak kurang dari $10 \mathrm{~cm}$ dari posisi sensor ultrasonik. Pada 
penelitian lainnya penggunaan sensor ultrasonik dimanfaatkan untuk mempelajari intensitas bunyi [11].

\section{SIMPULAN}

Karakterisasi sensor ultrasonik yang telah dilakukan dengan menggunakan mikrokontroler arduino uno, maka dapat disimpulkan bahwa sensor ultrasonik yang digunakan dapat mengumpulkan data dengan baik pada jarak $5 \mathrm{~cm}-100 \mathrm{~cm}$ dengan kesalahan relatif sebesar 5,57\%. Sedangkan untuk pengukuran cepat rambat bunyi menggunakan alat praktikum pengukur cepat rambat bunyi, didapatkan data pengukuran cepat rambat bunyi pada jarak penghalang $5 \mathrm{~cm}-100 \mathrm{~cm}$ menunjukkan rata-rata cepat rambat bunyi sebesar $342,99 \mathrm{~m} / \mathrm{s}$ dengan kesalahan relatif sebesar $0,0041 \%$. Hal tersebut menunjukkan bahwa alat praktikum pengukur cepat rambat bunyi dengan menggunakan

\section{REFERENSI}

[1]. A. D. Astuti, "Pengembangan Alat Eksperimen Cepat Rambat Bunyi Dalam Medium Udara Dengan Menggunakan Metode Time of Flight (TOF) dan Berbantuan Software Audacity," Unnes Physics Education Journal, vol. 5, no. 3, pp. 18-24, 2016.

[2]. Arsyad, "Media Pembelajaran (Revisi)," Jakarta: Rajawali Pers, 2014.

[3]. Jamaluddin, A. Kade \& Nurjannah, "Analisis Pelaksanaan Praktikum Menggunakan Kit IPA Fisika Di SMP Se-Kecamatan Sojol Kabupaten Donggala," Jurnal Pendidikan Fisika Tadulako (JPFT), vol. 3. no. 1, pp. 6-13, 2015.

[4]. E. Mulyatiningsih, "Metode Penelitian Terapan Bidang Pendidikan," Bandung: Alfabeta.

[5]. R. Simanjuntak, D. Desnita, and E. Budi, "The Development of Web-based Instructional Media for Teaching Wave Physics on Android Mobile”, JPPPF (Jurnal Penelitian dan Pengembangan Pendidikan Fisika), vol. 4, no. 1, pp. 1 - 10, Jun. 2018.

[6]. Y. R. Denny, I. S. Utami, S. Rohanah, and D. Muliyati, "The Development of Blended Learning Model using Edmodo to Train Student Critical Thinking Skills on ImpulseMomentum Topic", JPPPF (Jurnal Penelitian dan Pengembangan Pendidikan Fisika), vol. 6, no. 1, pp. 113 - 120, Jun. 2020.

[7]. S. Siswoyo, "Development of Teacher Guidebook for Photoelectric Effects Instructional Using Predict-Observe-Explain Strategy with PhET Interactive Simulation", JPPPF (Jurnal Penelitian dan Pengembangan Pendidikan Fisika), vol. 5, no. 2, pp. 133 - 144, Nov. 2019.

[8]. U. Pratiwi and D. Nanto, "Students' Strategic Thinking Ability Enhancement in Applying Scratch for Arduino of Block Programming in Computational Physics Lecture ", JPPPF (Jurnal Penelitian dan Pengembangan Pendidikan Fisika), vol. 5, no. 2, pp. 193 - 202, Dec. 2019.

[9]. Sulanjari, "Rancang Bangun Alat Penentu Cepat Rambat Gelombang Bunyi di Udara Menggunakan Tabung Impedansi," Jurnal Teknik Mesin: CAKRAM, vol. 1, no. 1, pp. $17-21,2018$.

[10]. Andayani et al., "Kalibrasi Sensor Ultrasonik HC-SR04 Sebagai Sensor Pendeteksi Jarak Pada Prototipe Sistem Peringatan Dini Bencana Banjir," Prosiding Seminar Nasional Fisika (E-Journal), vol. 5, pp. 43-46, 2016.

[11]. R. Athiyyah, T. Al Farizi, and D. Nanto, "Improvement of Science Process Skills Through Sound Variable Intensity Level Tool Kit", JPPPF (Jurnal Penelitian dan Pengembangan Pendidikan Fisika), vol. 6, no. 1, pp. 89 - 96, Jun. 2020. 